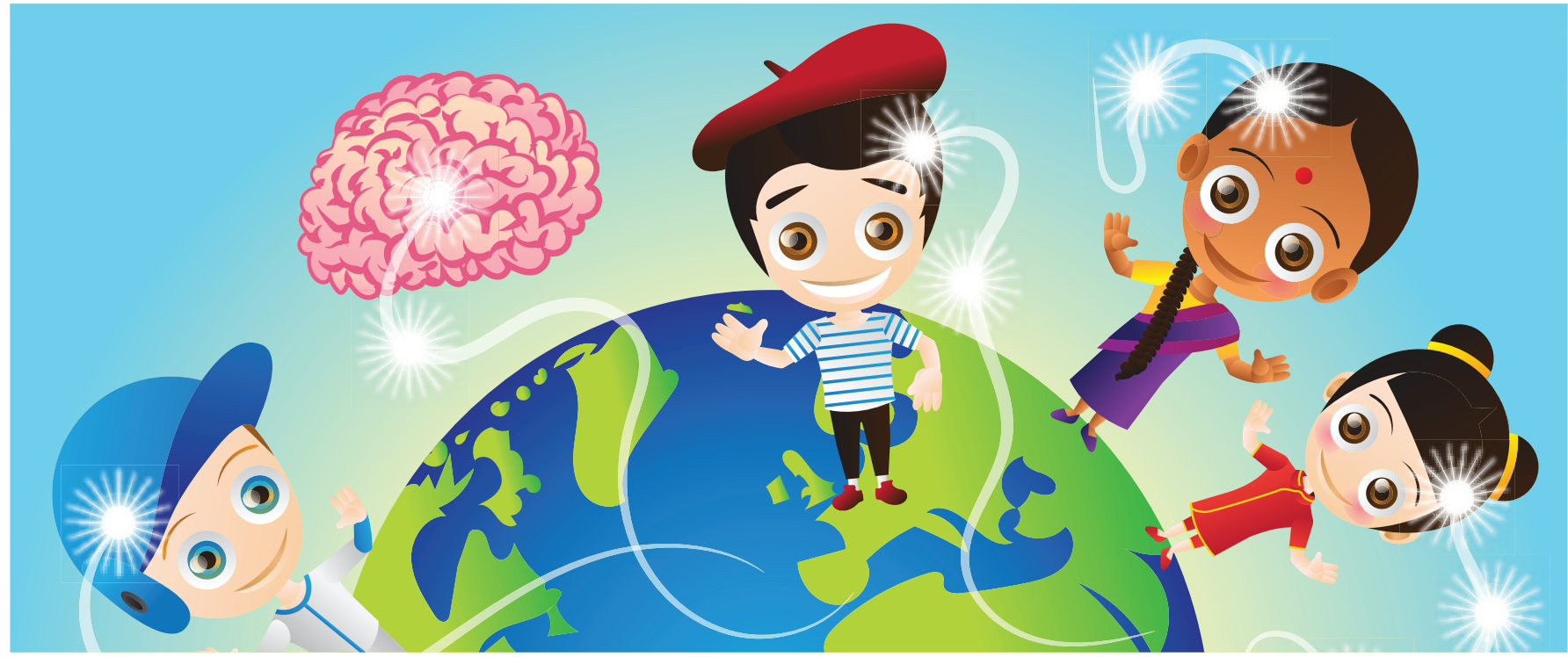

\title{
THE BRAIN AND THINKING ACROSS CULTURES
}

\section{Dominik Güss}

Department of Psychology, University of North Florida, Jacksonville, FL, USA

\section{REVIEWED BY:}

MARSHALL

ELEMENTARY

9-10 YEARS OLD
People from different cultures often do things quite differently. During the last decades, there has been research about how people around the world see the world and make decisions. What are similarities and cultural differences in thinking and where do they come from? We refer to three different studies. All these studies show cross-cultural differences and how the experiences that we have growing up in a specific cultural environment can influence how we think. Even if we are not aware of it, culture influences are how we see the world and what decisions we make.

In some countries, people eat roasted cockroaches, in others rabbits, in others dog meat. In some countries, adolescents fall in love and decide to spend the rest of their lives together. In other countries, the parents choose the partner whom you are supposed to marry. In some countries, when you schedule to meet someone at 2 p.m., you are actually supposed to be there at 2 p.m. In other countries, you are supposed to be there perhaps around 3 or 4 or even 5 p.m.

The knowledge people have about food preferences, partnership, and punctuality is stored in the brains of people. These cultural differences do not mean that the brains of people from different countries would actually look different, but all the knowledge, everything we learn is stored in our brain and thus the stored knowledge is different. Since the knowledge people acquire is stored in the human brain, the brain can be regarded as the center of culture. 


\section{WHAT IS CULTURE?}

Culture is knowledge used to cope with the world and each other, shared by a specific group of people, and passed on from generation to generation [1]. Cultures differ in their norms (what people are supposed to do in certain situations, e.g., greetings or what to eat) and values (what people regard as important, e.g., protecting the honor of the family or who to marry), but people from different cultures also differ in their thinking. Cross-cultural psychologists are scientists who study how people around the world are similar or different (also in terms of their thinking) and where those similarities and differences come from [2].

\section{CULTURAL DIFFERENCES IN PERCEPTION}

Perception refers to the human senses and how people see, hear, taste, and smell parts of the outside world. Even basic brain processes, such as the way people see the lines in the Müller-Lyer Figure (Figure 1), are influenced by culture. In the Müller-Lyer figure, the upper horizontal line is often seen as being shorter than the lower horizontal line even though both lines have equal length. The angled lines at the end of the horizontal lines can make some people see the horizontal lines as being different lengths.

People from western societies, who grow up in environments with buildings and corners, more often fell for the Müller-Lyer illusion - that is, they thought that the bottom line was longer than the top line, compared to people from cultures who live in round huts and tents or who live in the rain forest [3].

Newer studies also show cultural differences in perception of a scene, meaning which parts of their environment they focus on or see. Specifically, some people focus on the main object in front of them (foreground) and some on the surrounding objects (background). Researchers showed Americans and Japanese an animated underwater scene on the computer screen [4]. The scene showed fish (foreground) and water snails, plants, stones (as background) (Figure 2). Participants were shown this animated scene twice for $20 \mathrm{~s}$. Then, participants reported what they saw. Americans talked more often about the fast moving fish. Japanese talked more often about the background. Participants from areas in Eastern Asia, like Japan, more often perceive a scene as a whole, taking in both the foreground and the background, compared to Americans, who mainly perceive the object in the foreground.

The Müller-Lyer illusion. It is used to test visual illusions. Usually people see the upper horizontal line as being shorter compared to the lower horizontal line due to its inward pointing arrow heads. Both horizontal lines, however, have equal length.

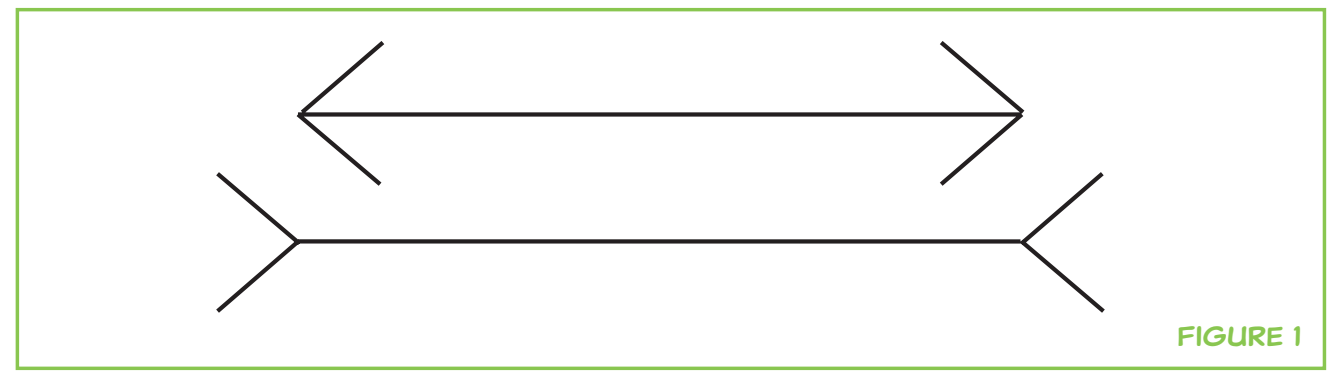




\section{FIGURE 2}

Underwater scene - still picture from the animated scene shown on the computer screen [4], reprinted with permission. The moving fish are regarded as the main objects, the foreground. The plants, stones, and water snails are regarded as the background.

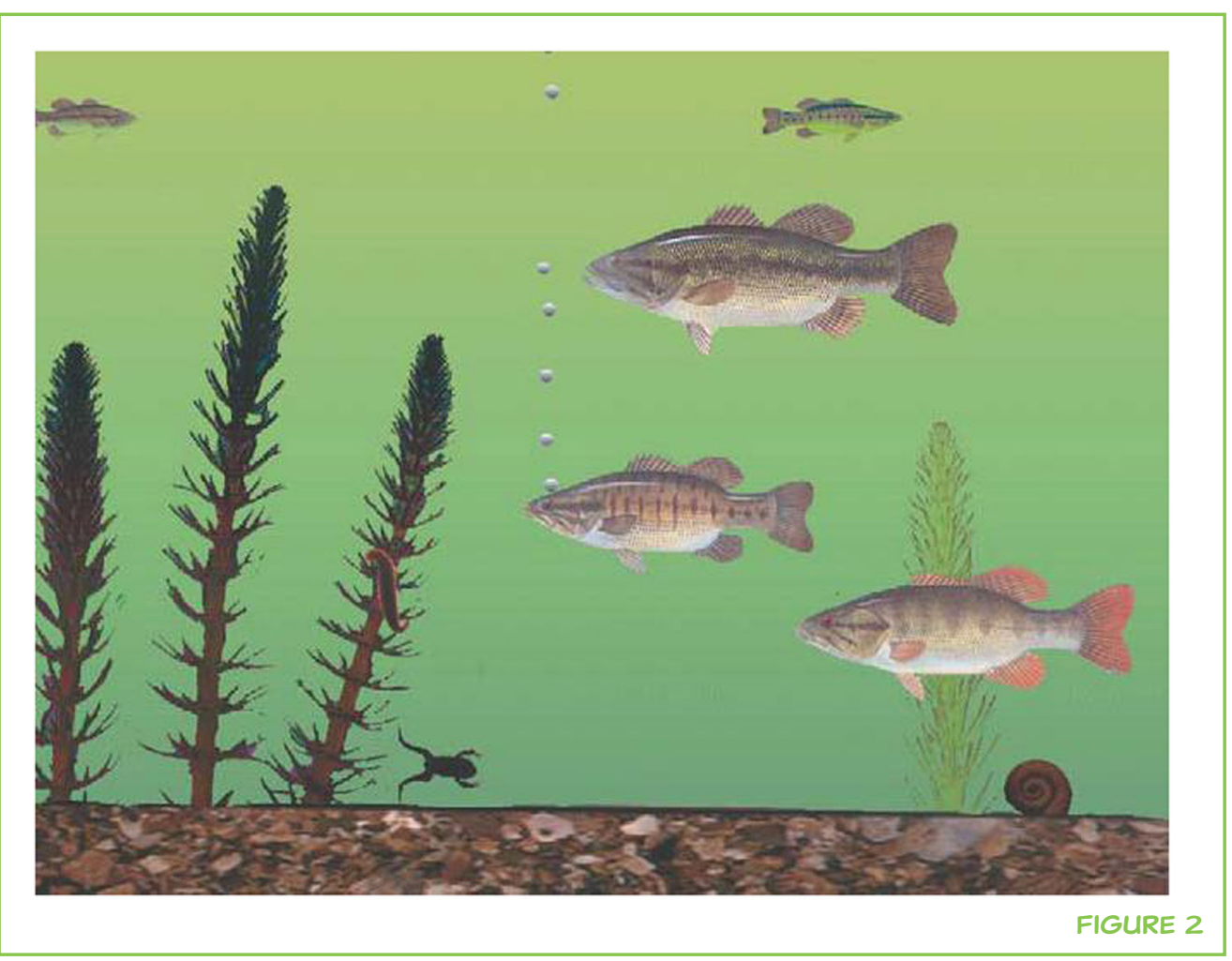

\section{CULTURAL DIFFERENCES IN DYNAMIC DECISION-MAKING AND EMOTIONS}

Not only is perception influenced by culture but also more complex thought processes, such as problem solving and making dynamic decisions. A static decision is whether I buy a KitKat or a Snickers bar in a grocery. Dynamic decisions are those that are made over time in a changing environment, for example, when you think about what profession you might want to choose later in your life. This decision might change depending on who you meet, who you talk to, what you read about certain jobs, what jobs your parents have, or what your friends want to become. Another example of dynamic decision-making is what a fire-fighting commander does. The fire-fighting commander has to make many decisions to fight wild fires depending on, for example, how big or small these fires are, their location near or far from cities, the weather and wind, which can make the fire burn faster or slower, the number of fire-fighting trucks and helicopters, and how fast they can go, and the amount of water they have to extinguish the fire.

Güss and colleagues had over 500 students in Brazil, India, the Philippines (three more collectivistic countries; countries that value more the group, family, and others), Germany, and the United States (two more individualistic countries; countries that value more each person's own goals and independence) work on two computer-simulated problem scenarios [1]. In one scenario, participants took the roles of fire-fighting commanders who had to protect cities from approaching fires (Figure 3). Everyone was seated in front of a computer screen and could give commands using the mouse during the $11 \mathrm{~min}$ of the 
simulation. They could give orders to their fire-fighting units and helicopters, for example, where they should go, which fires they should extinguish, whether they should tank water from the lakes or whether they should cut down trees to prevent fires from spreading. While participants worked on the simulation they spoke out loud everything that went through their minds, for example, "Mhh, there is no fire. Ah, no, I see one fire starting. Oh no, it is close to the city. What shall I do? Ok, I send a truck and a helicopter to extinguish the fire..." Everything they said was recorded and then written down word for word.

When the researchers analyzed these thinking-aloud protocols from all participants, they first found that when people make decisions in a difficult situation, they also feel emotions, often negative emotions, such as anger or frustration, sometimes positive emotions when they succeed and are happy with their decisions. Second, the researchers found differences between people from different cultures. Indian and Filipino participants more frequently described the problem situation (e.g., "There is a fire") and more often searched for information (e.g., "Does the truck still have enough water?"). German participants, on the other hand, talked more often about plans and goals (e.g., "First, I will send truck number 5 to the fire, and then I will send the helicopter to the city to be in a strategically good position.") and they rarely talked about their emotions. Americans more often mentioned goals and positive emotions ("Great! I did a good job!"). Brazilians, compared to all other participants, most often expressed negative emotions (e.g., "Oh nooo. I will never be a good firefighting commander.")

Where do these cultural differences come from? Why do people from some cultures mention more goals and plans, and why do others talk more about

\section{FIGURE 3}

FIRE training version with description of objects, still scene of the FIRE simulation at the start and after a few minutes when the fires start burning [5], reprinted with permission. The fires burnt already many trees and houses as seen on the right screen.

The yellow helicopters and the red trucks can extinguish the fires.

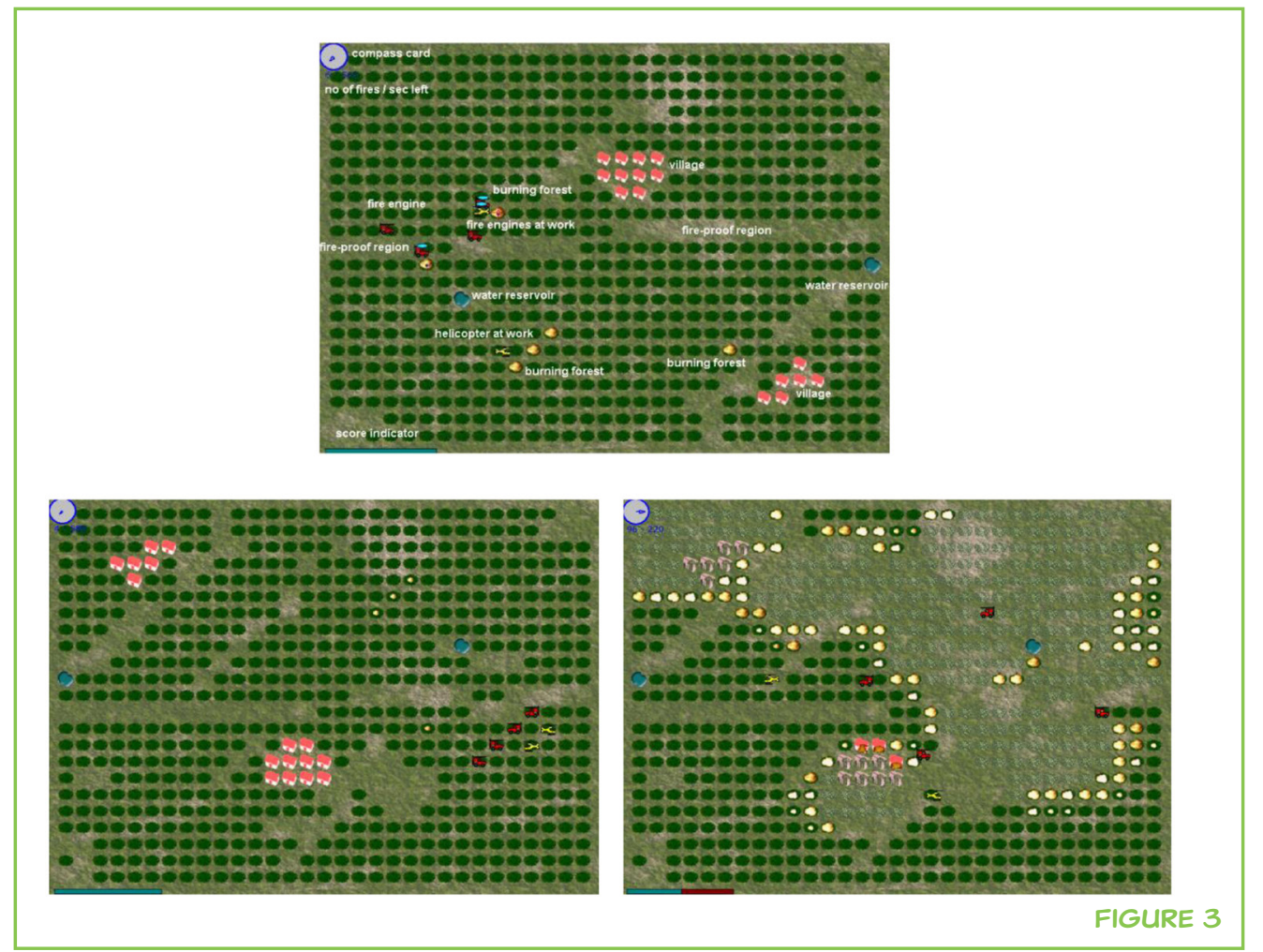


their emotions? Researchers tested and confirmed a model stating that the values we are taught by the culture we grow up in influence our problem solving and decision making styles [6]. Cultures that value the importance of each person's own goals and independence, for example, were related to making more decisions and more detailed planning compared to cultures that value the importance of group and others.

\section{CONCLUSION}

The three studies described here - the Müller-Lyer Illusion, figure-ground perception, and dynamic decision-making - show that these mental (and sometimes emotional) processes are happening within a certain culture and are influenced by the experiences we have living in a specific cultural environment. So sometimes we might think we make decisions, but it is more the cultural experiences stored in our brain that make our decisions. Even if we are not aware of it, culture influences how we see the world, what decisions we make, how we approach problems, and how we solve them. Do you think whether you play soccer or basketball, or whether you choose to eat chips or strawberries, or whether you study to be a nurse or a manager could be influenced by culture?

\section{REFERENCES}

1. Güss, C. D., Tuason, M. T., and Gerhard, C. 2010. Cross-national comparisons of complex problem-solving strategies in two microworlds. Cogn. Sci. 34:489-520. doi: 10.1111/j.1551-6709.2009.01087

2. Berry, J. W., Poortinga, Y. H., Breugelmans, S. M., Chasiotis, A., and Sam, D. L. 2011. Cross-Cultural Psychology: Research and Applications. 3rd ed. Cambridge, IN: Cambridge University Press.

3. Segall, M. H., Campbell, D. T., and Herskovits, M. J. 1966. The Influence of Culture on Visual Perception. Indianapolis, IN: The Bobbs-Merrill Company.

4. Nisbett, R. E., and Miyamoto, Y. 2005. The influence of culture: holistic versus analytic perception. Trends Cogn. Sci. 9:467-73. doi: 10.1016/j.tics.2005.08.004

5. Schaub, H. 2005-2015. Firefighting computer simulation game.

6. Güss, C. D. 2011. Fire and ice: testing a model on cultural values and complex problem solving. J. Cross Cult. Psychol. 42:1279-98.

doi: 10.1177/0022022110383320

SUBMITTED: 16 May 2015; ACCEPTED: 23 July 2015;

PUBLISHED ONLINE: 24 August 2015.

CITATION: Güss, CD (2015) The brain and thinking across cultures.

Front. Young Minds 3:12. doi:10.3389/frym.2015.00012

COPYRIGHT @ 2015 Güss. This is an open-access article distributed under the terms of the Creative Commons Attribution License (CC BY). The use, distribution or reproduction in other forums is permitted, provided the original author(s) or licensor are credited and that the original publication in this journal is cited, in accordance with accepted academic practice. No use, distribution or reproduction is permitted which does not comply with these terms. 


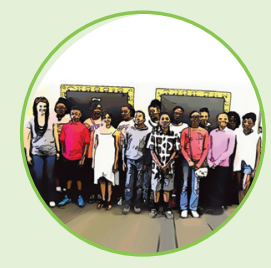

\section{REVIEWED BY}

\section{MARSHALL ELEMENTARY, 9-10 YEARS OLD}

Marshall Elementary School serves over 800 students from grades Pre-K through 5th grade. The students who review this article are in Mrs. Thomas' 4th grade class. These students have worked hard this year, incorporating literacy into the classroom by reading and analyzing news articles pertaining to our current topics and completing science labs to enhance their learning experiences. This opportunity to review a science article and work with our mentor in Switzerland has served as a wonderful culminating experience for the students!

\section{AUTHOR}

\section{DOMINIK GÜSS}

I was born and raised in Germany and have lived in the U.S. for more than 10 years now. As a scientist, I study how culture influences how people make decisions and solve problems. When I travel to other countries and talk to people, I have always been fascinated by how they do things differently and curious about how they see and think about the world. I feel blessed that I can pursue this fascination professionally. In my free time, I enjoy swimming, playing the piano, playing Lego and Bionicles with my two boys (age 4 and 10), and especially traveling with my family, who is indeed multicultural (my wife was born in the Philippines, my boys in the U.S., and I in Germany). 